\title{
Cuentos y leyendas escritas para los niños: un testimonio manuscrito de la presencia de Pe- rrault y Mme d'Aulnoy en el ámbito hispánico
}

\author{
José Vicente SALIDo LóPEZ \\ Universidad de Castilla-La Mancha \\ josevicente.salido@uclm.es \\ https://orcid.org/oooo-ooo1-9165-6176
}

\section{Resumen}

El presente trabajo estudia los Cuentos y leyendas escritas para los niños, una traducción decimonónica de varios cuentos de Mme d'Aulnoy y de Charles Perrault llevada a cabo por Francisco Alejandro Fernel. Se trata de un manuscrito compuesto en 1857, cuando aún eran escasos los testimonios de los dos autores franceses en español, lo que permite encontrar en él aportaciones novedosas en lo referente a su divulgación en el ámbito hispánico. Además, a partir del análisis comparativo de los contenidos, buscamos extraer conclusiones sobre los intereses y la finalidad de la obra, sobre los gustos personales del traductor y sobre las tendencias de la época en cuestiones de estilo.

Palabras clave: recepción, traducción, educación literaria, cuento tradicional, literatura infantil

\section{Résumé}

Cette étude analyse les Cuentos y leyendas escritas para los niños, une traduction du XIX ${ }^{\mathrm{e}}$ siècle de plusieurs contes de Mme d'Aulnoy et Charles Perrault réalisée par Francisco Alejandro Fernel. Il s'agit d'un manuscrit composé en 1857, alors que les témoignages des deux auteurs français en espagnol étaient encore rares. Cela nous permet d'y trouver de nouvelles contributions à propos de sa diffusion dans la sphère hispanique. De plus, à partir de l'analyse comparative des contenus, nous avons l'intention de tirer des conclusions sur les intérêts et le but de l'œuvre, sur les goûts personnels du traducteur et sur les tendances stylistiques de l'époque.

Mots clé : réception, traduction, éducation littéraire, conte traditionnel, littérature d'enfance

\section{Abstract \\ The present work studies the Cuentos y leyendas escritas para los niños, a nineteenth-century translation of several stories by Mme d'Aulnoy and Charles Perrault conducted by Francisco Alejandro Fernel. It is a manuscript composed in}

${ }^{*}$ Artículo recibido el 22/03/2021, aceptado el 1/06/2021. 
1857, when the testimonies of the two French authors in Spanish were still scarce, which makes it possible to find novel contributions regarding its dissemination in the Hispanic sphere. In addition, from the comparative analysis of the contents, we seek to draw conclusions about the interests and the purpose of this work and about the stylistic tastes of the translator and of the nineteenth century.

Keywords: reception, translation, literary education, traditional tales, children's literature

\section{Introducción}

El 30 de noviembre de 1857, Francisco Alejandro Fernel, el polifacético autor y traductor de nuestro siglo XIX (Salido, 2020), firmaba la dedicatoria y el prólogo de sus Cuentos y leyendas para niños ${ }^{1}$, un manuscrito que contiene cinco relatos que titula como Micifuf (pp. 25-46), El príncipe Jorobeta (pp. 49-69), Pulgadilla (pp. 73-103), La rana benéfica (pp. 108198) y La puerca Cenicienta (pp. 202-235, aunque, por error en la paginación, 236). Todos son traducciones de textos franceses, en concreto de las colecciones de cuentos maravillosos que en el final del siglo XVII recopilan Charles Perrault y Mme d'Aulnoy.

No era la primera vez que se traducía la obra de estos autores al español, pero por entonces los testimonios aún eran escasos y parciales, lo que nos permite encontrar en este manuscrito contribuciones originales y de relativo interés para la tradición de los dos cuentistas en la cultura hispánica.

Precisamente, uno de los objetivos que nos planteamos en el presente trabajo es analizar el valor de esas aportaciones, ya que, aunque la presencia de Perrault y Mme d'Aulnoy en el ámbito español es un asunto que ya se ha abordado, siempre ha sido a partir de testimonios impresos. Además, mediante un análisis comparativo con los textos originales, nos proponemos extraer conclusiones sobre la finalidad y los intereses ideológicos y estéticos con los que Fernel pudo proyectar esta obra relativamente novedosa en su contexto.

\section{Aportación del manuscrito a la tradición de Perrault y Mme d'Aulnoy en el ámbito hispánico}

Si tomamos como referencia el panorama europeo, puede comprobarse que el género del cuento maravilloso tardó en asentarse en la cultura hispánica (Vicens, 2014), un hecho aplicable tanto a la producción autóctona como a la tradición importada. Por ejemplo, en el caso de Perrault, el autor ya se conocía en Italia a la altura de 1727, cuando se edita en Venecia una colección miscelánea de sus cuentos (Mattarucco, 2018); en lengua in-

\footnotetext{
${ }^{1}$ La obra se conserva en los fondos de la Biblioteca Nacional de España con la signatura $\mathrm{MSS} / 23036$.
} 
glesa se traducen por primera vez en 1729 , cuando Robert Samber los publica con el título Histories or Tales of Passed Times (Bottigheimer, 2002); en alemán circulaban desde 1754; en neerlandés existía edición bilingüe desde 1790 (Ghesquière, 2006); y en portugués, aparecen traducciones de El gato con botas en 1820 (Lisboa, Impressão Regia) y de Piel de asno en 1821 (Lisboa, Impressão de Alcobia) (Cortez, 2001; da Silva, 2014). Pero en español no será hasta 1824 cuando se imprima la primera traducción de las Histoires ou contes du temps passé, más de ciento veinticinco años después de que se publicaran por primera vez en su versión original.

Esa primera edición en español es una traducción anónima que, además de tardía, ni siquiera se imprime en España; será el taller parisino de I. Smith el que ponga el colofón a esta versión que incluye los ocho cuentos de las Histoires de Perrault. A partir de ahí, se publican en ese siglo XIX al menos once traducciones más, casi todas en la segunda mitad, y con el nombre de su autor desde la titulada Cuentos de Carlos Perrault, incluida en la colección de la Biblioteca Universal (Perrault, 1851-1852).

Y algo parecido ocurre con la obra de Mme d'Aulnoy, que solo cuenta con dos traducciones en el siglo XIX, quitando la de Fernel. Son Bella Bella o El caballero afortunado (trad. José Llorente. Logroño, Viuda de Brieva, 1844) y los Cuentos de Madama de Aulnoy (Madrid, Imprenta de la Biblioteca Universal, 1852), donde, además de una breve noticia biográfica sobre la autora (1ab-2a), se incluyen los cuentos La bella de los cabellos de oro (2a-4b), El ramo de oro (5a-10a), El buen ratoncillo (10a-12b), El carnero (13a-15b), Fineta, la cenicienta (pp. 15b-19b), La princesa Rosita (20a22b), El pájaro azul (22b-29a) y La gata blanca (29a-34b).

Por tanto, para cuando Fernel redacta su manuscrito ya circulaban versiones en español de uno y otra ${ }^{2}$, pero que no fuera pionero en la traducción de los dos autores no impide reconocerle otros valores que sí le corresponden. Uno de ellos, relacionado con los textos de Perrault, es el de ser su primer traductor conocido, porque todas las versiones anteriores se habían publicado sin datos del autor de la traducción. Hasta la de José Coll y Vehí (Perrault, 1862), ninguna edición impresa de los cuentos de Perrault en es-

\footnotetext{
2 De Perrault existía la edición publicada en París en 1824, la titulada Barba Azul o La llave encantada (Valencia, Cabrerizo, 1829), que se reedita un año después, y la que aparece en el Semanario Pintoresco dentro de la Biblioteca Universal (Madrid, 1851-1852). Martens (2016), que ha analizado con detalle las traducciones de Perrault, incluye en su estudio estas tres ediciones anteriores a 1857, pero no tiene en cuenta la reedición de 1830 de Barba Azul o La llave encantada. Roas (2000), en su catálogo de traducciones decimonónicas de la obra de Charles Perrault, no recoge la edición de Barba Azul o La llave encantada de 1829, pero sí la de 1830. También refiere unos Cuentos de hadas (París, Garnier, 1840) que no hemos podido localizar. En nuestras cuentas, consideramos las tres ediciones que relaciona Martens, más la reedición de la de 1829.

Para el caso de Mme d'Aulnoy, antes de la traducción de Fernel circulaban las dos ediciones decimonónicas que acabamos de referir.
} 
pañol ofrece datos del traductor, lo que significa que cinco años antes, aunque en formato manuscrito, Francisco Alejandro Fernel ya había firmado su versión de los cuentos del escritor parisino. Y sobre la traducción de $L a$ grenouille bienfaisante, el cuento de Mme d'Aulnoy, su valor radica en que desde esta no se conoce otra versión en español hasta las que aparecen en los Cuentos de hadas (Aulnoy, 1979) y en El serpentón verde y otros cuentos de hadas (Aulnoy, 1984), ya en las últimas décadas del siglo XX (Vicens, 2014).

Obviamente, el hecho de que el manuscrito no se imprimiera restó impacto a sus aportaciones, pero ello no invalida los méritos que le hemos reconocido ni le quita importancia a las conclusiones que pueden extraerse de la obra en relación con el interés que despertaron los dos autores franceses y con la finalidad que se les dio a sus cuentos en la España del siglo XIX.

\section{Intereses del traductor y finalidad de la obra}

Para conocer los intereses que movieron a Fernel a la hora de componer esta obra son esenciales las noticias que se dan en la dedicatoria y en el prólogo (Fernel, 1857: 7-9 y 11-21).

El volumen está dedicado a la infanta D. ${ }^{\text {a }}$ María Isabel Francisca de Asís, conocida popularmente como «la Chata», a la que Fernel, seguramente por equivocación, llama por el nombre de su madre, la reina Isabel II ${ }^{3}$. Por la fecha en la que se firma el manuscrito, era la única hija viva de la reina, aunque el 28 de noviembre de 1857, es decir, dos días antes de la rúbrica de Fernel, había nacido el infante Alfonso, el que con los años llegaría a ser el rey Alfonso XII. Así, puede suponerse que la intención de nuestro traductor fue dirigirse al miembro más joven de la familia real, que por entonces era una niña de seis años.

El interés que motivó esta dedicatoria puede intuirse a partir de lo que cuenta en su inicio, cuando dice que «con el objeto de distraer las lentas horas de mi prisión, concebí la idea de emprender el imperfecto trabajo que hoy tengo el atrevimiento de dedicar a V. A.» (Fernel, 1857: 7). Por lo que sabemos de su biografía, al hablar de su prisión no lo hacía metafóricamente, lo que nos lleva a suponer que la elección de la destinataria se hizo buscando un beneficio personal concreto.

Aún en tiempos de Fernando VII, Fernel ya había gozado del favor real con diversos encargos como joven de lenguas que le sirvieron para formarse por toda Europa en diplomacia y en idiomas. Años más tarde, durante las regencias en la minoría de edad de Isabel II y en los primeros años de su reinado, también recibió distintos nombramientos como jefe de la Gobernación de varias provincias españolas. Pero en la década de los 50, una vez

\footnotetext{
3 La portada (p. 3), dibujada a pluma con letra ornamental, ofrece los datos fundamentales de la obra: «CUENTOS Y LEYENDAS Escritas para los Niños y Dedicadas a S. A. SERENISIMA LA YNFANTA D. ${ }^{\mathrm{a}}$ MARIA YSABEL LUISA POR D. ${ }^{\mathrm{n}}$ Fran..${ }^{\mathrm{co}}$ Alejandro Fernel. Madrid 30 de noviembre de 1857».
} 
finalizados sus mandatos políticos, se embarcó en diversas empresas particulares, entre ellas la dirección de varias sucursales del Monte de Piedad. No sabemos si la mala gestión o las malas prácticas tuvieron que ver con que a la altura de 1855 se decretara en el Boletín Oficial de Madrid el cierre de las oficinas, pero el caso es que el negocio fracasó y el 7 de agosto de $1857 \mathrm{se}$ publicaba en La Gaceta de Madrid el concurso de acreedores para los clientes afectados por las pérdidas.

Es decir, por las fechas y por los hechos parece que cuadran las circunstancias en las que reconoce que ideó el manuscrito, lo que nos permite suponer que su intención al dedicarlo a la infanta fue la de recuperar el favor regio y el estatus social del que había gozado en otros momentos más prósperos de su vida.

A partir de esos indicios hemos podido plantear una hipótesis sobre sus intereses, pero cuestión diferente es por qué elige precisamente un género como el del cuento maravilloso y por qué se fija en estos dos autores de la tradición francesa. En definitiva, cuál es la utilidad que pensó para sus textos.

En este sentido, resulta especialmente útil la información que aporta en el prólogo, donde declara su intención de atender a la educación de la infancia:

La cuestión más importante para la sociedad, la que siempre ocupó, y con razón, la atención de todos los gobiernos, la que desvela a todo padre de familia, el objeto, en fin, al que ningún otro puede compararse es la educación de la infancia (Fernel, 1857: 11).

Fernel, además de político, traductor y empresario, fue también un profesional de la educación que en distintos momentos de su vida se dedicó a la instrucción de la juventud como director y profesor en varios colegios y academias de Sevilla y Madrid. Su concepto de la enseñanza lo materializó en una formación integral para sus alumnos que trascendía la mera adquisición de contenidos o habilidades prácticas. Y en su convencimiento de que «la educación modela el corazón» (Fernel, 1857: 13), encuentra en el cuento el género ideal para llevar a cabo la tarea formativa, porque, «vistiendo la sana moral con imágenes risueñas, sencillas y entretenidas, dando cuerpo y acción a la virtud, han conseguido inspirarla a la infancia, juntamente con la sensibilidad y caridad, hijas del corazón y no del entendimiento» (Fernel, 1857: 13).

Esta visión instrumentalizada de la literatura para niños cuadra con la concepción que tradicionalmente se tenía de las lecturas infantiles, que llevaban aparejado el componente pedagógico como un rasgo inherente. La idea, a pesar de ser antigua, aún marcaba las pautas de la literatura para niños en la época de Fernel, cuando ya pueden encontrarse obras específicas para un destinatario infantil (López-Tamés, 1990). Tradicionalmente, las primeras lecturas habían consistido en textos instrumentales que, más que 
una función de entretenimiento o de educación literaria, buscaban la enseñanza moral, doctrinal o didáctica (Bravo-Villasante, 1989); y para el deleite, servía lo que Juan Cervera (1991) etiquetó como literatura ganada, esto es, un conjunto de obras escritas para un público adulto en las que el lector infantil encontraba disfrute. No obstante, estas lecturas ganadas no siempre contaban con la aprobación de los preceptores, que encontraban algunos géneros, autores u obras poco apropiados para la sensibilidad infantil, por mucho que despertaran su interés. Ejemplos nos da santa Teresa, que en su Vida cuenta cómo su padre le prohibía leer libros de caballerías (Teresa de Jesús, 2010: 19), o Pedro Malón de Echaide, el moralista español que en el prólogo de El libro de la conversión de la Magdalena (1588) censura que las niñas lean «libros lascivos y profanos» como los de Garcilaso, Boscán o Jorge de Montemayor ${ }^{4}$. Fernel, más de dos siglos después, repite esta idea casi al pie de la letra, primero en su crítica a las lecturas durante la infancia de las novelas de Balzac, Victor Hugo o Dumas (Fernel, 1857: 15), y después al hablar de la formación moral de las niñas:

¿Verán los padres con punible indiferencia a sus tiernas hijas dedicadas a la lectura de Han de Islandia, Martín el Expósito y otros libros infinitamente más inmorales? ¿Habrá algún padre que ignore que la mayor belleza, el dote más pingüe que sus hijas pueden aportar al matrimonio, es la inocencia? ¿Y la podrá tener moralmente hablando la doncella que en la infancia haya nutrido su corazón con la lectura de algunos de los modernos novelistas franceses? ¿Dónde está el manto de pureza femenina que resistir pueda sin mancha a semejante lectura? (Fernel, 1857: 17-18).

En la época del agustino y de la santa, la censura moral sobre las lecturas infantiles se explica desde la Contrarreforma, que intensificó el control ideológico en todos los ámbitos, incluido el educativo (Salido, 2015: 222225; Vergara, 1993: 53-56). En los tiempos de Fernel las circunstancias ya eran otras y la actividad censora era más laxa, pero todavía quedan rastros de esa moral tradicional bien arraigada en la cultura hispánica. Además, se añade que en medio del ambiente liberal-progresista de las primeras décadas del siglo XIX la Iglesia anduvo atenta a la actividad editorial, incluyendo

4 «... así la ceban con libros lascivos y profanos, adonde y en cuyas rocas se rompen los frágiles navíos de los mal avisados mozos; y las buenas costumbres (si algunas aprendieron de sus maestros) padecen naufragios y van a fondo y se pierden y malogran. Porque, ¿qué otra cosa son los libros de amores y las Dianas, y Boscanes, y Garcilasos, y los monstruosos libros y silvas de fabulosos cuentos y mentiras de los Amadises, Floriseles y don Belianís, y una flota semejante de portentos como hay escritos puestos en manos de pocos años, sino un cuchillo en poder del hombre furioso? [...] ¿Qué ha de hacer la doncellita, que a pena sabe andar, y ya trae una Diana en la faldriquera? $\mathrm{Si}$, como dijo el otro poeta, el vaso nuevo se empapa y conserva mucho tiempo el sabor del primer licor que en él se echare, siendo un niño y una niña vasos nuevos, y echando en ellos vino tan venenoso, ¿̇no es cosa clara que guardarán aquel sabor largo tiempo?» (Aladro, 1997: 176-177). 
en su vigilancia las traducciones para evitar la llegada de obras con aires liberales y para potenciar la divulgación de obras europeas que se consideraban edificantes (Hibbs, 2011: 150). Estas circunstancias permiten entender la postura moralista de Fernel y su interés por el cuento como género que aúna entretenimiento y enseñanza.

Para cuando se redacta el manuscrito, el cuento infantil ya contaba con algunos autores de cierto prestigio dentro de nuestras letras, con nombres tan ilustres como los de Fernán Caballero, Juan Eugenio Hartzenbusch o Antonio de Trueba. Pero Fernel solo cita como caso raro en la literatura española a Francisco Martínez de la Rosa:

Cierto es que algunos sabios que figuran con justicia entre nuestros más eminentes literatos y que han adquirido una reputación europea, convencidos de la falta que deploro, no se han desdeñado de dar el ejemplo escribiendo cuentos. Citaré entre otros al excelentísimo señor don Francisco Martínez de la Rosa. ¿Quién creyera que tan ilustre ejemplo carecería de imitadores? (Fernel, 1857: 14).

El desconocimiento o la desconsideración de ese caudal de la cuentística hispánica es lo que motiva que Fernel acuda a la tradición europea, donde parece manejarse mejor, en busca de cuentos que cumplan esa doble función instructiva y lúdica que entiende como principio elemental de la literatura para niños:

Penetrados de estas ideas que yo no he hecho sino bosquejar, las naciones más ilustradas de la moderna Europa abundan en obras expresamente escritas para la infancia en las que se encuentra felizmente harmonizada la moral con una lectura entretenida, fácil y risueña. ¿Por qué, pues, no sucede lo mismo en España? ¿Será acaso porque nuestros ingenios consideran este trabajo como pueril e indigno de su elevado talento? iLastimoso y fatal error! (Fernel, 1857: 16).

Curiosamente, los textos que elige no estaban pensados en su origen para un destinatario infantil (Garrido Carrasco, 2015: 94; Garrido Carrasco, 2019: 470; Regard, 2011: 118), pero Fernel encuentra en ellos un modelo de lectura edificante que, convenientemente tratada, puede servir para la formación desde el entretenimiento. Esa fue su intención, según declara en este prólogo y según se intuye, como vamos a ver, a partir de diversas estrategias traductológicas que aplica al verter al español los textos originales.

\section{Los cuentos}

La selección de títulos que prepara Fernel buscaba la adecuación a los intereses y capacidades de lectores de distintas edades: 
Finalmente, deseando que mis cuentos puedan acomodarse a la inteligencia, utilidad y recreo de niños de diferentes edades (por ejemplo, de 5 a 12 años), los he dividido en tres series. Abraza la primera cuentecitos propios para la más tierna edad, como Micifús, Pulgadilla, etc.; la segunda, cuentos de hadas y encantadores como La rana benéfica, Jorobeta, El príncipe querido, etc.; y la tercera se compone de leyendas portentosas como $\mathrm{Ge}$ noveva, El jabalí infernal, La novia cadáver, etc. (Fernel, 1857: 19-20).

Del plan original completa la primera parte; de la segunda, cambia Le prince Chéri, de Mme Leprince de Beaumont, por Cendrillon, de Perrault; y de la tercera no hemos tenido más noticias que las que da aquí, probablemente porque no llegó a ver la luz. Tampoco sabemos exactamente a qué obras se refiere ni cuál podía ser la fuente de la que pensaba tomar los textos 5 .

En el caso de los cuentos que llegó a traducir, sabemos que los vierte del francés, porque, aunque ya circulaban versiones en español de prácticamente todas las obras que selecciona, es probable que no las conociera, a tenor de lo que dice el propio autor: «Puedo asegurar que, aun cuando muchas de ellas, como ya he tenido la buena fe de decirlo, no son sino imitaciones, ninguna ha sido conocida hasta hoy en nuestro idioma» (Fernel, 1857: 20).

No parece que tuviera intención de mentir cuando erróneamente se atribuye el mérito de ser el primer traductor de Perrault y Mme d'Aulnoy al español, y si mentía, lo que es seguro es que no se sirvió de ninguna de las versiones españolas en las que podría haberse inspirado. Sus textos son resultado de un ejercicio de traducción personal que muy probablemente realizó a partir del volumen XXXVI de Le cabinet des fées, de Charles Joseph de Mayer (s. a.). Se trata de una colección de 34 cuentos de distintos autores franceses que recoge los cinco que traduce Fernel: Le chat botté (p. 8), Riquet à la houppe (p. 9), Le petit Poucet (p. 22), La grenouille bienfaisante (p. 24) y Cendrillon (p. 29). No es la única vez que los cuentos de Perrault y de Mme d'Aulnoy se editan en volúmenes misceláneos ${ }^{6}$, pero esta

5 Posiblemente, Genoveva sea el cuento de Genoveva de Brabante, obra del alemán Christoph von Smith que, para cuando Fernel escribe este prólogo, ya contaba con traducción al francés. El jabalí infernal nos plantea más dudas; pudiera tratarse del cuento de Andersen titulado El jabalí de bronce, aunque no termina de encajar el título que le da con la leyenda que cuenta el escritor danés. Y de La novia cadáver tampoco es mucho lo que podemos aportar. En toda Europa hay leyendas tradicionales sobre desposados por burla con cadáveres o de bodas de ultratumba por promesas incumplidas en vida. Pero no hemos dado con ningún cuento culto que nos sirva como fuente para este proyecto de traducción.

${ }^{6}$ The child's Fairy Library (6 vols. London: Joseph Thomas, 1837) incluye varios cuentos de Perrault y de Mme d'Aulnoy, pero no La grenouille bienfaisante. Ocurre igual con Les contes de Perrault, de Mme d'Aulnoy et de Madame Leprince de Beaumont (Passard Paris : Hilaire le Gai, 1852) (Alzati, 2018). 
edición recoge todos los del manuscrito y en el mismo orden en que son traducidos; además, incluye Le prince Chéri (p. 1), el cuento de Mme Leprince de Beaumont que Fernel anuncia en el prólogo, pero que no llega a traducir.

A partir de estas evidencias, entendemos que la antología de Le cabinet des fées fue el original sobre el que trabajó Fernel y a esta edición nos remitiremos para llevar a cabo el análisis comparativo de los textos con el que intentamos comprobar la hondura de su aportación y los intereses de sus intervenciones.

Nos centraremos, en primer lugar, en el estudio de los títulos, por la información que dan sobre las posibles influencias en el traductor y sobre su aportación en la fijación de su forma moderna; después, abordaremos el análisis traductológico de los textos para ver el calibre y la función de las operaciones de Fernel en el original francés.

\subsection{Los títulos}

En el siglo XIX, los cuentos de la tradición francesa todavía no eran muy conocidos entre el público español, lo que hace que cada traductor o editor dispusiera de relativa libertad al trasladar sus títulos (Barcia, 1998; Martens, 2016: 186). Esa autonomía afecta también a los dos autores que nos ocupan.

En el caso de Le chat botté, la traducción de Fernel es la primera que da nombre al personaje principal del cuento, al que llama Micifuf. Las tres traducciones anteriores se refieren al protagonista como El gato maestro o con botas (Perrault, 1824; 1829) o Maese Gato o el gato con botas (Perrault, 1851-1852). Después de la de Fernel, la traducción de De la Vega (Perrault, 1863) lo llama Micifuz, y así aparece en otras que se basan en esta de 1863 , como la de Garnier (Perrault, 1884) o la de la Biblioteca Universal (Perrault, 1892)7. La de Baró (Perrault, 1883) es la otra edición decimonónica que también nombra al gato, aunque lo hace llamarse Maese Zapirón.

A pesar de la coincidencia, no parece que la traducción de Fernel tenga que ver con el título que aparece en las versiones posteriores a la de 1863, primero porque el manuscrito de nuestro autor debió de contar con una difusión prácticamente nula, y segundo, porque la coincidencia no es significativa, en tanto que el nombre de Micifuz ya contaba por entonces con una larga trayectoria como zoónimo ${ }^{8}$.

En la tradición hispánica, ese nombre había servido para otros gatos célebres como el protagonista de la Gatomaquia, de Lope de Vega, que hace pareja con Marramaquiz y que aparece de nuevo en la silva tercera de las Rimas del licenciado Tomé Burguillos enrazado con Zapirón, «el gato

7 Por una cuestión de operatividad, tomamos en consideración únicamente las ediciones del siglo XIX.

${ }^{8}$ El nombre se relaciona etimológicamente con la voz micho, que el Diccionario de Autoridades define como "voz con que se llama, acaricia y halaga al gato», o miz / mizo, que es «lo mismo que gato o gata» (Aut., s. v.), y con fu, que es voz onomatopéyica «para imitar el bufido del gato» (DRAE, s. v.). 
blanco y rubio / que, después de las aguas del diluvio / fue padre universal de todo gato» (Vega, 1990: 330). Más próxima a los años en los que escribe Fernel es la fábula de los gatos escrupulosos que compone Samaniego y que protagonizan, de nuevo, la pareja de Micifuz y Zapirón.

En esa tradición debió de inspirarse Fernel para nombrar al protagonista de su traducción, aunque con la doble particularidad de no llamarlo Micifuz, forma más habitual del nombre, sino Micifuf, y de presentar una vacilación ortográfica entre Micifuf y Micifús. Como Micifuf aparece en el índice y en el título, peritextos que, con seguridad, se incluyeron después de la composición del cuerpo de la traducción. En el texto, en 17 ocasiones se lo llama también Micifuf, aunque en todas se corrige sobre la forma Micifús, que aparece en las páginas 30 y 45, posiblemente porque, una vez decidido a unificar el nombre como Micifuf, debió de saltarse esas menciones. Quizá la variante que se da en el manuscrito procede de una contaminación con la palabra fufo, «bufido del gato» (DLE, s. v.), que pudo serle más familiar a nuestro traductor o resultarle más expresiva para nombrar a su protagonista. En cualquier caso, su fórmula no ha contado con mucha fortuna en las traducciones posteriores.

En el caso de Riquet à la houppe, la traducción de Fernel se titula $E l$ príncipe Jorobeta. Antes se había conocido como Riquet del copete (Perrault, 1824; 1829) y Riquet el del moño (Perrault, 1851-1852), manteniendo en el título el antropónimo original del protagonista. Esta tendencia es la misma del resto de traducciones decimonónicas, que, en el mejor de los casos, se limitan a castellanizar el nombre como Roquete (Perrault, 1862; 1883). Fernel opta por un título de cosecha propia, alejado del original, aunque mejor relacionado con el contenido del texto, al servirse de un nombre parlante que da cuenta de uno de los defectos físicos más característicos del personaje.

El cuento de Le petit Poucet es traducido como Pulgadilla, con un empleo del diminutivo como estrategia expresiva que sigue el patrón de las traducciones anteriores, que titulan el cuento como Pulgarcillo (Perrault, $1824 ; 1829 ; 1851-1852)$. Y las posteriores de ese siglo, en general, hacen lo mismo, usando este último título (Perrault, 1867) o alguno similar, como Pulgarito (Perrault, 1863; 1883; 1884; 1892). Solo hay dos versiones que ofrecen fórmulas más originales, como Meñiquín (Perrault, 1883), que busca una hipérbole expresiva, o Caga-chitas (Perrault, 1862; 1876), que bautiza al protagonista a partir de una de sus acciones dentro de la trama.

En cuanto al título del cuento de Mme d'Aulnoy, La grenouille bienfaisante, no hay modelos ni referencias anteriores que pudieran haber inspirado a Fernel en su traducción. Lo traslada de manera literal como $\mathrm{La}$ rana benéfica, de manera muy similar a la que aparece en las dos siguientes versiones españolas de este texto, la de los Cuentos de hadas (Aulnoy, 1979) y la de El serpentón verde (Aulnoy, 1984), que lo titulan La rana bienhechora. 
Por último, el cuento de Perrault Cendrillon ou la pantoufle de verre es titulado como La puerca Cenicienta, un título que busca una intensificación expresiva que no tienen los de las traducciones anteriores, más fieles a la versión original. Las tres traducciones previas lo titulan La Cenizosa o la chinelilla de vidrio (Perrault, 1824; 1829) y Cenicienta o la zapatilla de cristal (Perrault, 1851-1852). Después, el cuento se llamó La Cenicienta o la chinelita de cristal (Perrault, 1862; 1876), Cenicienta o la zapatilla enana (Perrault, 1863; 1884; 1892), La Cenicienta o la chinelita de vidrio (Perrault, 1867), Cenicienta (Perrault, 1883) o La Cenicienta y la chinela de cristal (Perrault, 1883). Así, Fernel es el único traductor decimonónico que rompe la tendencia conservadora y se atreve a intervenir de manera más libre en la traducción del título para enriquecerlo con la connotación negativa de la protagonista que intensifica la expresividad del texto.

Precisamente esta intensificación expresiva, que vemos en el título de este cuento de La puerca Cenicienta o en el de El príncipe Jorobeta, es una de las características que singulariza a los cuentos de la tradición hispánica en relación con los de otras tradiciones europeas (Hormaechea, 2000: 191192; Martens, 2016: 166-168; Pascua, 1998: 158), por lo que puede entenderse como una intervención del traductor para adaptar los textos a la cultura de recepción. Y este mismo interés se percibe también, aunque por otro método, en el caso de Micifuf, que desde el título establece una relación intertextual con diversas obras de la tradición hispánica.

\subsection{Los textos}

Sobre la traducción de los cinco cuentos, en una visión general se observa la fidelidad con que Fernel trata los originales en el plano de la integralidad, donde no se detectan intervenciones que supongan una modificación estructural reseñable.

No obstante, en un análisis traductológico más preciso es posible documentar acciones que se concretan en tres funciones principalmente9: la adaptación del texto a los referentes y gustos estéticos de la cultura meta, la función didáctica y el refuerzo del mensaje moral.

En cuanto a la inclusión de elementos propios de la cultura de recepción, se realiza, en unos casos, como estrategia de sustitución de determinados elementos de la cultura original que no serían entendibles en el ámbito

\footnotetext{
9 Simplificamos mucho el análisis por una cuestión de operatividad y de extensión, aunque estamos trabajando en estudios más específicos que se centran de manera precisa en otras intervenciones del traductor destinadas a solventar problemas como posibles dificultades de lectura para un receptor infantil, elementos relacionados con la facilitación de la narración oral o con el ajuste a los estereotipos del género de la cuentística en la tradición hispánica. No obstante, los ejemplos más significativos en relación con la finalidad de la obra son los que tienen que ver con la adaptación cultural y estilística de los textos, con el factor didáctico y con los mensajes doctrinales, de los que solo podemos dar una muestra para ejemplificar cada caso.
} 
para el que se traduce. Así, vemos ejemplos de equivalentes culturales relacionados con el ámbito de la gastronomía ( $p a ̂ t e ́ ~=>$ almondiguillas), de los espectáculos (mascarades $=>$ toros y cañas) o de la botánica (jasmins $=>$ rosas; jonquilles $=>$ claveles):

$$
\text { TO (texto original) }
$$

...vous serez tous hachés menu comme chair à pâté (Le chat botté, $8 \mathrm{~b})^{10}$.

L'on y faisait des mascarades, des courses de bagues, des tournois... ( $L a$ grenouille bienfaisante, 28a).

...métamorphosés en fleurs, qui ne baladinaient pas moins, jasmins, jonquilles, violettes, œillets et tubéreuses... (La grenouille bienfaisante, 27a).

En otros casos, comprobaremos este fenómeno de adaptación en la additio de elementos que son cotidianos y reconocibles para los lectores de la traducción, aunque en esta ocasión la finalidad de la intervención es el reconocimiento del texto original como propio del polisistema en el que se integra. Los añadidos son de muy diversa índole y van desde referencias literarias al uso de topónimos familiares, de paremiología autóctona o de referentes comunes en el contexto de recepción:

TO

...cachant sous ses ailes des fleurs admirables (La grenouille bienfaisante, 26a).

...sur le plus beau cheval du monde ( $L a$ grenouille bienfaisante, 28a).

...mais l'épée de dix-huit aunes était d'une si bonne trempe, qu'il la maniait comme il voulait... (La grenouille bienfaisante, 29a).

Le chat continua ainsi pendant deux où trois mois à porter de temps en
TM

...trayendo oculta bajo sus alas una colección de flores más preciosas que las que hay en las estufas del Campo del Moro (La rana benéfica, 137).

...sobre el mejor caballo de la Cartuja de Jerez (La rana benéfica, 170).

...era aquella una espada que hubiera atravesado al mismo peñón de Gibral$\operatorname{tar}$ (La rana benéfica, 192).

De este modo continuó Micifuf por espacio de dos o tres meses llevando de

${ }^{10}$ Para las referencias a los textos, incluimos entre paréntesis el título y el número de página en el que aparece en la edición de Le cabinet des fées, y, en la traducción, el título del cuento y el número de página del manuscrito. 
temps au roi du Gibier de la chasse de son maître (Le chat botté, $8 \mathrm{~b}$ ).

À peine fut-il couché, qu'il eut contentement ; un jeune étourdi de lapin entra dans son sac, et le maître chat tirant aussitôt les cordons le prit et le tua sans miséricorde (Le chat botté, 8a).

Sa marraine la creusa, et n'ayant laissé que l'écorce, la frappa de sa baguette, et la citrouille fut aussitôt changée en un beau carrosse tout doré (Cendrillon, 29b). cuando en cuando regalillos al rey, persuadido de la verdad de aquel adagio: Dádivas quebrantan peñas, y seguro de que llegaría el día de recoger con usura lo que entonces sembraba (Micifuf, 32-33).

Un conejo mozo y rollizo, de los más jaques, menospreciando los consejos de sus mayores, se metió osadamente en el morral y se puso a comer a dos carrillos, riendo y mofándose del miedo de los demás. Micifuf le dejó engullir algunos bocados y luego, tirando repentinamente de los cordones, quedó cerrado el moral y Juan Cigarrón ${ }^{11}$ cayó en la percha (Micifuf, 29-30).

Puso esta la calabaza en el suelo y, pegando en ella con su báculo, la Cenicienta vio con indecible asombro que se transformaba en la más elegante carretela que jamás salió de los salones de Fatterschall ${ }^{12}$ de Londres ( $L a$ puerca Cenicienta, 217-218).

Sobre la adaptación a los gustos estéticos del contexto de recepción, de manera general se puede demostrar con abundantes y variados ejemplos la tendencia al incremento de la expresividad, rasgo característico de la cuentística española que ya hemos señalado al hablar de los títulos. Los casos van desde el aumento de la adjetivación al uso de la sinonimia, de la hipérbole, de la comparación o de la modificación del estilo directo e indirecto con intención expresiva. La casuística es, pues, muy variada y nos impide abordar en este trabajo un análisis exhaustivo del tratamiento estilístico que hace Fernel del TO. No obstante, presentamos una muestra que ejemplifica el fenómeno:

TO

Pendant qu'on retirait le pauvre marquis de la Rivière, le chat s'approcha du carrosse, et dit au roi que

\section{TM}

Y mientras lo hacían, acercose el gato con mucha gracia al coche, saltó al estribo, se puso en dos pies y, asomando

\footnotetext{
${ }^{11}$ Se trata de un cuento popular de tradición castellana que por su fama dio origen a la expresión «De esta hecha, Juan Cigarrón cayó en la percha». Quiere decir «que para el hombre más avisado y sagaz hay alguna ocasión peligrosa de la cual no saldrá airoso fiado de su habilidad o destreza» (Montoto, 1921-1922: II, 24).

${ }^{12}$ Aunque no hemos podido localizar estos salones londinenses, por el contexto queda claro que se trataba de una marca de carruajes que debía de tener cierto renombre en España, lo que nos permite incluir el ejemplo entre los de familiarización con el contexto de recepción.
} 
dans le temps que son maître se baignait, il était venu des voleurs qui avaient emporté ses habits, quoiqu'il eût crié au voleur de toute sa forcé ; le drôle les avait cachés sous une grosse pierre (Le chat botté, 8b).
Il était fort petit (Le petit Poucet, 22a-b).

Dès qu'elle y fut, elle la guérît avec une liqueur dont elle la frotta ( $L a$ grenouille bienfaisante, 25a)

...qui tremblait de toute sa forcé... (Le petit Poucet, 28a).

...ne put s'empêcher de rire de l'opinion où elle était d'être morte ( $L a$ grenouille bienfaisante, 24b). el hocico por la portezuela, saludó primero con la más fina galantería a la princesa, luego hizo presentes sus respetos al rey y le dio cuenta de cómo su amo, que era muy aficionado a nadar, se había echado al río, dejando la ropa a su cuidado por haber ido sin ninguno de sus gentiles hombres, que unos ladrones que, sin duda, estaban al acecho, atraídos por la riqueza de los vestidos (no tenía miedo que se descubriera el embuste porque ya había cuidado él de enterrarlos donde nadie pudiera hallarlos), tan luego como vieron bien lejos al nadador se echaron sobre ellos y se los llevaron, a pesar de su esforzada resistencia. A sus gritos y al ruido de la refriega, su amo, viendo y conociendo lo que pasaba, se puso a nadar desesperadamente hacia la orilla, esperando, no obstante que se hallaba a inmensa distancia, llegar a tiempo para castigar la osadía de aquellos bergantes. Pero cuando ya había recorrido las dos terceras partes de la distancia, le faltaron las fuerzas o le acometió de súbito algún calambre, de modo que, a no ser por la providencial llegada de S. M., indudablemente hubiera perecido víctima de su afición al agua (Micifuf, 34-36).

Había nacido tan pequeñín y diminuto... (Pulgadilla, 74).

...sacó un cierto ungüento con el que frotó las contusiones y desolladuras que tenía la reina... (La rana benéfica, 120).

Temblaba de miedo como un azogado... (Pulgadilla, 87).

...soltó una carcajada tan salvaje y estrepitosa, que hizo huir asustados a todos los animales en dos leguas a la redonda (La rana benéfica, 118). 
Il alla ensuite les présenter au roi, comme il avait fait le lapin de garenne. Le roi reçut encore avec plaisir les deux perdrix, et lui fit donner pour boire (Le chat botté, 8b). ...con las que de nuevo se dirigió a palacio, teniendo, como la primera vez, la honra de ser recibido en audiencia particular por el monarca. iSeñor! -dijo haciendo sus acostumbradas reverencias-. Mi amo, el marqués de Valdedioses, ruega humildemente a V. M. se digne recibir este par de perdices que ha cazado en una de sus numerosas heredades (Micifuf, 31-32).

En lo que atañe a la intencionalidad didáctica, son también varios los ejemplos en los que el traductor se sirve de la additio para incluir contenidos con un evidente interés formativo. Se trata, por norma general, de referencias culturales que, aunque pueden tener una función expresiva, delatan el interés por la presentación de contenidos que buscan aumentar los conocimientos historiográficos, literarios o culturales del lector infantil:

TO

Les noces ne furent pas plus tôt faites, que la belle-mère fit éclater sa mauvaise humeur; elle ne put souffrir les bonnes qualités de cette jeune enfant, qui rendaient ses filles encore plus haïssables (Cendrillon, 29b).

Le gentilhomme qui faisait l'essai de la pantoufle, ayant regardé attentivement Cendrillon, et la trouvant fort belle, dit que cela était juste, et qu'il avait ordre de l'essayer à toutes les filles (Cendrillon, 30b).

La princesse n'eut pas plus tôt prononcé ces paroles, que Riquet à la Houppe parut, à ses yeux, l'homme du monde le mieux fait et le plus aimable qu'elle eût jamais vu (Riquet à la Houppe, 10b).

(Sin equivalente en el TO)
TM

Hízolo al fin y desde entonces murió domésticamente el buen caballero sin esperanza de resurrección, y su pobre e inocente hija quedó reducida a peor condición que la de un ilota (esclavo entre los romanos) o un paria (casta maldita en la India, de cuyos individuos todo el mundo huye más que si fueran leprosos) en su propia casa. ( $\mathrm{La}$ puerca Cenicienta, 202).

El comisario, aunque si [sic] la más leve esperanza no atreviéndose a omitir diligencia alguna, rogó a la señora la mandase a llamar. Hízose así y compareció la Cenicienta sucia y mal aperjeñada, pero más bonita que Hebea o Psiquis (La puerca Cenicienta, 231).

No bien hubo la princesa pronunciado estas palabras, cuando Jorobeta apareció a sus ojos más hermoso que el mismísimo Apolo de Belvedere (El príncipe Jorobeta, 68).

Si alguno llegara a dudar de la veracidad de esta historia maravillosa, séame lícito recordarles la de Bernardotte en nuestros días, que de panadero que era 
en pan, sin ausilio [sic] de brujas, hadas ni encantadores ha llegado a ocupar el trono del famoso Carlos XII, rey de Suecia; y la del inglés Wittington, tan verídica, sin duda, como la de Micifuf, que de aprendiz de carpintero o zapatero, no recuerdo bien cuál de los dos, y por la gracia de otro gato y nada más, llegó a ser corregidor de Londres, bonito destino que yo aceptaría con mucho gusto aun cuando para ir a desempeñarlo tuviera que dejar mi boardilla (Micifuf, 45-46).

Queda, por último, la aportación del traductor en lo que tiene que ver con el contenido moralizante, muy presente aún en la época de Fernel en las numerosas reelaboraciones cultas de cuentos folclóricos y en las traducciones de relatos de otras tradiciones. Su función era ajustar el texto a los parámetros educativos del momento (Amores, 2001: 105-107 y 131-152; Amores y Amores, 2014: 458-480). En esencia, se trata de enseñanzas relacionadas con la formación en los preceptos del cristianismo y de valores tradicionales como el amor filial, la humildad, la resignación y, en el caso de las mujeres, el recato y la discreción:

TO

Le chat qui entendait ce discours, mais qui n'en fit pas semblant, lui dit d'un air posé et sérieux : Ne vous affligez point, mon maître, vous n'avez qu'à me donner un sac, et me faire faire une paire de bottes pour aller dans les broussailles, et vous verrez que vous n'êtes pas si mal partagé que vous croyez (Le chat botté, 8a).

Il mit du son et des lasserons dans son sac, et s'étendant comme s'il eût été mort, il attendit que quelque jeune lapin, peu instruit encore des ruses de ce monde, vint se fourrer dans son sac pour manger ce qu'il y avait mis ( $L e$ chat botté, 8a).

\section{TM}

Sin embargo, oyolo el gato, quien, nada edificado con los proyectos de su nuevo amo, conoció lo mucho que le interesaba disuadirle cuanto antes de sus planes económicos, y así le dijo:

-¿A qué viene esa aflición, señor amo? $¿$ ¿ree V. que sus hermanos han heredado mejor que V.? Pues sepa que no hay nada tan espuesto [sic] como el fiarse en las apariencias (Micifuf, 27).

Los gazapillos no tardaron en venir a triscar y saltar por encima de él, pero los conejos viejos, más sagaces y precavidos, aunque les incitaba fuertemente la vista y el olor del salvado y trébol que el gato había echado en el fondo del morral, no cayeron en la tentación de irle a comer; antes bien, amonestaron a los más jóvenes para que no lo hicieran. Pero la juventud siempre fue muy presuntuosa e imprudente (Micifuf, 29). 
Dès le lendemain, les noces furent faites, ainsi que Riquet à la Houppe l'avait prévu, et selon les ordres qu'il en avait donnés longtemps auparavant (Riquet à la Houppe, 10b).

Après avoir fait pendant quelque temps le métier de courrier, et y avoir amassé beaucoup de biens, il revint chez son père, où il n'est pas possible d'imaginer la joie qu'on eut de le revoir. Il mit toute sa famille à son aise. Il acheta des offices de nouvelle création pour son père et pour ses frères ; et par là il les établit tous, et fit parfaitement bien sa cour en même temps (Le petit Poucet, 24a).

Il était une fois un gentilhomme qui épousa en secondes noces une femme, la plus hautaine et la plus fière qu'on eût jamais vue. Elle avait deux filles de son humeur, et qui lui ressemblaient en toutes choses (Cendrillon, 29a).

Le mari avait de son côté une jeune fille, mais d'une douceur et d'une bonté sans exemple; elle tenait cela de sa mère, qui était la meilleure personne du monde (Cendrillon, 29a). ...celebrándose espléndidamente las bodas; y el matrimonio fue feliz porque en él se unieron la sabiduría en el hombre con la discreción, hermosura y recato de la mujer (El príncipe Jorobeta, 69).

Fue tanta la alegría del rey, de la corte y del pueblo y tan grande el servicio público de Pulgadilla, que el rey no solo le cumplió las promesas que le había hecho, sino que le señaló estados considerables que redituaban crecidas rentas y le creó barón del imperio.

El leñador y su mujer, vestidos como señores, vivieron como tales, gracias al amor filial de Pulgadilla. Todos sus hermanos fueron educados y ocuparon buenos destinos y el señor barón, que llegó a ser un hombre muy instruido y considerado, se casó a su tiempo con una señorita de la primera nobleza y vivió largos y felices años (Pulgadilla, 100-103).

Este era un caballero viudo, rico y de distinguido nacimiento que tenía una hija de tierna edad, pero de maravillosa hermosura. Como la niña iba creciendo y no era decente dejarla sola en casa cuando él estaba fuera, es decir, la mayor parte del día y de la noche, conoció que no le quedaba otro recurso sino el volverse a casar, lo cual era para él tanto más necesario cuanto que su genio apacible, descuidado y generoso no le permitía luchar con los criados ni vigilar con el esmero necesario la economía de la casa y el cuidado de sus haciendas (La puerca Cenicienta, 202203).

Dios, siempre misericordioso, había dotado a esta niña de una hermosura sobrehumana y de un carácter angelical, como lo necesitaba para soportar los horribles padecimientos a que la 
La fée dit alors à Cendrillon : "Hé bien, voilà de quoi aller au bal, n'es-tu pas bien aise ? Oui, mais est-ce que j'irai comme cela avec mes vilains habits ? "Sa marraine ne fit que la toucher avec sa baguette, et en même temps ses habits furent changés en des habits de drap d'or et d'argent tout chamarrés de pierreries ; elle lui donna ensuite une paire de pantoufles de verre, les plus jolies du monde (Cendrillon, 30a).

Je viens, s'écria-t-elle, pour couronner la fidélité de la princesse Moufette, elle a mieux aimé exposer sa vie, que de changer ; cet exemple est rare dans le siècle où nous sommes, mais il le sera bien davantage dans les siècles à venir (La grenouille bienfaisante, 29a).

Sa marraine qui la vit toute en pleurs, lui demanda ce qu'elle avait. Je voudrais bien... je voudrais bien... Elle pleurait si fort qu'elle ne put achever. Sa marraine, qui était fée, lui dit : Tu voudrais bien aller au bal, n'est-ce pas ? Hélas oui, dit Cendrillon en soupirant. Hé bien, seras-tu bonne fille ? dit sa marraine, je t'y ferai aller (Cendrillon, 29a). debilidad de su padre la condenaba ( $L a$ puerca Cenicienta, 208).

Acercósela la viejecita y, tocándola suavemente con el báculo, se halló instantáneamente convertida en una dama tan espléndida, tan ricamente vestida y peinada, que la reina más poderosa del mundo no podía comparársela. [...] En una palabra, la riqueza indescribible de su traje era solo comparable con su hermosura celestial.

Para aumentar su asombro, se apareció de repente un magnífico espejo de cuerpo entero en el que pudo contemplarse de pies a cabeza.

Su madrina la concedió unos instantes para que se repusiera y la dijo: -Ya ves, hija mía, cómo el Cielo, tarde o temprano, da a toda virtud su recompensa (La puerca Cenicienta, 219-221).

Vengo, dijo, para premiar la fidelidad de nuestra querida Angélica, que prefirió sacrificar su vida más bien que faltar a su fe. Semejante rasgo de virtud es muy raro en nuestro siglo, pero lo será infinitamente más en los venideros (La rana benéfica, 197).

Sonriose la Cenicienta y contestó: -Ya ve usted, amada madrinita, qué buena facha tengo yo para ir a palacio.

-Sí, pero suponte que tuvieras elegantes vestidos y ricas joyas. ¿Sentirías el ir?

-En verdad, no lo sentiría, porque como nunca he ido a palacio, me alegraría de ver la magnificencia que allí habrá. Sin embargo, como eso no es posible, me consuelo con que mis hermanas, cuando vuelvan, me contarán lo que hayan visto.

-iNo harán tal! -exclamó la vieja levantándose y estrechando tiernamente a la Cenicienta contra su pecho-. iNo harán tal, ángel mío! Ya es tiempo de recompensar tu modestia, tu humildad 
y tu santa resignación (La puerca Cenicienta, 215-217).

Estos son algunos ejemplos que explican a grandes rasgos las intervenciones que opera Fernel en los textos originales de Perrault y Mme d'Aulnoy. Aunque no se trata de un análisis exhaustivo, nos permite comprobar las estrategias que aplica para conseguir la adaptación estética de los textos a su nuevo contexto de recepción y para enriquecer el componente doctrinal, moral y didáctico que caracterizó a buena parte de la literatura que a partir del siglo XIX empieza a componerse específicamente para el público infantil.

\section{Conclusiones}

A pesar de su escasa repercusión, Los cuentos y leyendas escritas para los niños son un testimonio de indudable interés por la aportación que suponen al estado de la cuestión sobre la presencia de Perrault y Mme d'Aulnoy en la cultura española y por las conclusiones que permiten sacar sobre la traducción y la educación literaria en el siglo XIX.

En cuanto al asunto de la entrada de los dos cuentistas franceses en nuestra cultura, este manuscrito ofrece el nombre del primer traductor conocido de los cuentos de Perrault al español y uno de los pocos que se dedicaron en el siglo XIX a la obra de Mme d'Aulnoy, además de ser el único que traduce La grenouille bienfaisante hasta que apareciera nuevamente en español más de un siglo después, en los Cuentos de hadas de 1979.

Y como obra de traducción, en ella hemos podido comprobar la libertad con la que Fernel se maneja en textos ajenos, un fenómeno que no es exclusivo de nuestro autor ni de esta obra. Más bien, puede entenderse como una tendencia general en la traducción literaria propia de la época, cuando los límites entre traducción y creación eran ciertamente difusos (Álvarez, 1997: 7-14; Botrel, 2010: 27-42; Hibbs, 2015: 197-233). Además, el fenómeno se acentúa en el caso del cuento, donde está demostrada la intensificación emotiva y expresiva que caracteriza al género en el ámbito hispánico a partir del estudio comparado de las adaptaciones de cuentos folclóricos que realizaron diversos autores del siglo XIX (Amores, 1997: 9-19) y de las versiones traducidas que circularon de los cuentos más célebres de la tradición francesa, principalmente (Hormaechea, 2000: 191-192; Martens, 2016: 166-168; Pascua, 1998: 158).

El hecho de que estos cuentos tradicionales no fueran aún conocidos en la cultura hispánica facilitaba esas intervenciones que eran cosecha del traductor, quien obraba con total libertad en los títulos y en los textos buscando siempre la adaptación del original a los intereses estéticos y pragmáticos del contexto de recepción.

En el caso de estas traducciones de Fernel, las acciones se centran en la familiarización del texto original con el polisistema literario que lo recibe a través del uso de referencias intertextuales propias de la cultura meta o de 
referentes comunes en el contexto de recepción. También afectan a la intencionalidad didáctica de la obra, declarada en el prólogo por el propio traductor. En este ámbito, se ha comprobado la presencia de numerosos añadidos de naturaleza cultural, ideológica, moral o doctrinal que terminan de explicar la esencia de la traducción y su utilidad para una educación literaria que por entonces buscaba sobre cualquier fin cumplir con el principio horaciano del docere et delectare.

\section{REFERENCIAS BIBLIOGRÁFICAS}

ALADRo FonT, Jorge (1997): Pedro Malón de Echaide y La conversión de la Magdalena (vida y obra de un predicador). Pamplona, Gobierno de Navarra.

Álvarez CAlleJA, María Antonia (1997): «El factor creativo en la traducción literaria». Atlantis, $19: 1,7-14$.

AlZATI, Valentina (2018): Les contes de Mme d'Aulnoy et leur fortune en Europe (France; Italie; Grande-Bretagne; Allemagne) 1752-1935. Tesis doctoral dirigida por Evanghelia Stead. París, Université Paris-Saclay.

AMORES, Montserrat (1997): Catálogo de cuentos folclóricos reelaborados por escritores del siglo XIX. Madrid, CSIC.

AMORES, Montserrat (2001): Fernán Caballero y el cuento folclórico. Puerto de Santa María, Ayuntamiento del Puerto de Santa María.

AMORES, Montserrat \& María Jesús AMOREs (2014): «El cuento folclórico al servicio de la moral en el Semanario Pintoresco Español». Castilla. Estudios de Literatura, 5, 458-480.

Aulnoy, Mme d' (1852): Cuentos de Madama de Aulnoy. Madrid, Imprenta de la Biblioteca Universal.

Aunoy, Mme d' (1979): Cuentos de hadas. Prólogo de Carmen Bravo-Villasante. Barcelona, Bruguera.

AulNoy, Mme d' (1984): El serpentón verde y otros cuentos de hadas. Traducción de José Benito Alique. Palma de Mallorca, Biblioteca de Cuentos Maravillosos.

BARCIA MENDO, Enrique (1998): «La recepción de los cuentos de Perrault: algunos problemas derivados de la traducción de Contes de ma mère l'Oye», in María Rosa Cabo Martínez (ed.), La literatura infantil yjuvenil: su proyección en el aula. Oviedo, Universidad de Oviedo, 253-260.

BOTREL, Jean François (2010): «La literatura traducida: ces española?», in Marta Giné Janer y Solange Hibbs-Lissorgues (coords.), Traducción y cultura. La literatura traducida en la prensa hispánica (1868-98). Berna, Peter Lang, 27-42.

BotTigheimer, Ruth B. (2002): «Misperceived Perceptions: Perrault's Fairy Tales and English Children's Literature». Children's Literature, 30, 1-18.

BRAVO-VILlaAsANTE, Carmen (1989): Ensayos de literatura infantil. Murcia, Universidad de Murcia. 
CERVERA, Juan (1991): Teoría de la literatura infantil. Bilbao, Mensajero.

CoRTEZ, Maria Teresa (2001): Os Contos de Grimm em Portugal. A Recepção dos Kinder-und Hausmärchen entre 1837 e 1910. Coimbra, Minerva-Centro Interuniversitário de Estudos Germanísticos-Universidade de Aveiro.

DA SILVA BÁRBARA, Maria Elisabete (2014): Os contos de Perrault em Portugal no Estado Novo. Tesis doctoral dirigida por Maria Teresa Mesquita y Maria António Hörster. Coimbra, Universidade de Coimbra.

FERNEL, Francisco Alejandro (1857): Cuentos y leyendas escritas para los niños. Manuscrito, Biblioteca Nacional de España, SIGN.: MSS/23036.

GARRIDO CARRASCO, Vicenta (2015): Mujeres y hadas: desde el cuento a las reivindicaciones femeninas. Jaén, Universidad de Jaén.

GARRIDO CARRASCO, Vicenta (2019): «El incesto en los cuentos de Perrault y de Mme d'Aulnoy». Arenal, 26: 2, 467-488.

GHESQUIÈRE, Rita (2006): «Why Does Children's Literature Need Translations?», in Jan Van Coillie y Walter P. Verschueren (eds.), Children's Literature in Translation. Manchester, St. Jerome Publishing, 19-33.

HIBBS, Solange (2011): «La traduction comme appropriation du texte: l'Église catholique espagnole et les enjeux de la traduction au XIX ${ }^{\mathrm{e}}$ siècle», in Michel Ballard (ed.), Censure et traduction. Arras, Artois Presses Université, 145158.

HIBBS, Solange (2015): «La traducción como mediación cultural en el siglo XIX: reflexiones epistemológicas y metodológicas sobre una práctica compleja», in Francisco Lafarga y Luis Pegenaute (eds.), Creación y traducción en la España del siglo XIX. Berna, Peter Lang, 197-233.

HORMAECHEA, Gabriel (2000): «Convenciones, tradición y emotividad en la traducción de cuentos de hadas», in Veljka Ruzicka Kenfel, Celia Vázquez García y María Lourdes Lorenzo García (eds.), Literatura infantil y juvenil: tendencias actuales en investigación. Vigo, Universidade de Vigo, 189-198.

LÓPEZ TAMÉs, Román (1990): Introducción a la literatura infantil. Murcia, Universidad de Murcia.

MARTENS, Hanna (2016): Tradición y censura en las traducciones de literatura infantil y juvenil en la cultura franquista: los cuentos de Perrault en español hasta 1975. Tesis doctoral dirigida por Enrique Barcia Mendo, José Soto Vázquez y Reine Meylaerts. Badajoz, Universidad de Extremadura.

MATTARUCCO, Giada (2018): «Capuccetto Rosso e di tutti i colori». ITALOGRAMMA, $15,207-225$.

MAYER, Charles Joseph de (s. a.): Le cabinet des fées. Vol. 41. París, Gustave Barba.

MONTOTO Y RAUTENSTRAUCH, Luis (1921-1922): Personajes, personas y personillas que corren por las tierras de ambas Castillas. Vol. 2. Sevilla, Gironés.

PASCUA FEBLES, Isabel (1998): La adaptación en la traducción de la literatura infantil. Las Palmas de Gran Canaria, Universidad de Las Palmas de Gran Canaria.

Perrault, Charles (1824): Cuentos de las hadas. París, I. Smith. 
PERrault, Charles (1829): Barba Azul o La llave encantada. Colección de cuentos maravillosos. Valencia, Librería de Cabrerizo.

Perrault, Charles (1851-1852): Cuentos de Carlos Perrault. Madrid, Biblioteca Universal.

PERRAult, Charles (1862): Cuentos de hadas. Traducción de José Coll y Vehí. Barcelona, Publicaciones ilustradas de La Maravilla.

PERrault, Charles (1863): Los cuentos de Perrault. Traducción de Federico de la Vega. París, Abel Ledoux.

Perrault, Charles (1872): Cuentos de las hadas. París, Librería de Rosa y Bouret.

Perrault, Charles (1883): Cuentos de hadas. Traducción de José Coll y Vehí. Barcelona, Librería de Juan y Antonio Bastinos.

Perrault, Charles (1884): Los cuentos de Perrault. París, Garnier.

Perrault, Charles (1892): Cuentos de Perrault. Madrid, Biblioteca Universal.

PERRAult, Charles \& Mme LePrince De BEAUMont (1867): Cuentos de las hadas. París, Garnier.

Perrault, Charles \& Mme LePrince De Beaumont (1883): Cuentos de Claudio Perrault y de Madama de Beaumont. Traducción de Cecilio Navarro. Barcelona, Luis Tasso y Serra.

REAl ACADEMIA EsPañola (1976): Diccionario de Autoridades. Edición facsímil. Madrid, Gredos. [AUT].

REAl ACADEMia EsPañola (2001): Diccionario de la Lengua Española. Madrid, Real Academia Española. [DLE].

REGARD, Gleen (2011): «The Fairy Tales of Madame d'Aulnoy (1892): la traduction des Contes des Fées et des Contes nouveaux de Marie-Catherine d'Aulnoy par Annie Macdonell et Elizabeth Lee». Féeries. Études sur le conte merveilleux, XVII ${ }^{e}-X I X^{e}$ siècle, 8, 117-134.

ROAS DEUS, David (2000): La recepción de la literatura fantástica en la España del siglo XIX. Tesis doctoral dirigida por Sergio Beser Orti. Barcelona, Universidad Autónoma de Barcelona.

SALIDO LÓPEZ, José Vicente (2015): «La literatura doctrinal y devocional en las escuelas del Barroco. El Memento mori como materia escolar». Historia de la Educación: Revista interuniversitaria, 34, 221-243.

SALIDO LÓPEZ, José Vicente (2020): «Sobre traducción decimonónica en España: semblanza bio-bibliográfica de Francisco Alejandro Fernel». Sendebar, 31, 251-270.

TERESA DE JESÚs, Santa (2010): Libro de su vida. Edición de Raúl Alonso. Alicante, Cántico.

Vega CARPIO, Lope de (1990): Lope de Vega esencial. Edición de Felipe Pedraza. Madrid, Santillana.

VERGARA CIORDIA, Javier (1993): «La Iglesia y la educación: el proceso de secularización docente», in Buenaventura Delgado Criado (coord.), Historia de la educación en España y América. Madrid, SM-Morata, 53-56.

VICENS PUJOL, Carlota (2014): «Recepción de la obra de Mme d'Aulnoy en España: traducciones y prólogos». Çédille, revista de estudios franceses, 10, 367- 
383. URL: https://www.ull.es/revistas/index.php/cedille/article/view/1486/979 